\title{
Benefícios da Musicoterapia no tratamento da afasia motora
}

\author{
Benefits of Music Therapy in the treatment of \\ motor aphasia
}

\section{Beneficios de la musicoterapia en el tratamiento de la afasia motora}

\author{
Giselle Loiacono Ramos de Azevedo, Michelle de Melo Ferreira², Rita \\ de Cássia dos Reis Moura ${ }^{3}$
}

1.Pós-Graduada em Musicoterapia Aplicada, Departamento de Música, Faculdade Santa Marcelina, São Paulo-SP, Brasil. Orcid: https://orcid.org/0000-0003-3330-9277

2. Musicoterapeuta, graduanda em Fonoaudiologia, mestre em Ciências pelo programa de pósgraduação em Psicobiologia, EPM/UNIFESP, professora do curso de pós-graduação em Musicoterapia Aplicada da Faculdade Santa Marcelina, São Paulo-SP, Brasil. Orcid: https://orcid.org/0000-0002-8413-5302

3.Doutorado pela Universidade Federal de São Paulo (UNIFESP), Coordenadora e Professora do curso de Pós-Graduação em Musicoterapia Aplicada, Departamento de Música, Faculdade Santa Marcelina, São Paulo-SP, Brasil. Orcid: https://orcid.org/0000-0003-0150-7586

\begin{abstract}
Resumo
Introdução. Afasia motora é uma das sequelas recorrentes do acidente vascular cerebral impactando a comunicação verbal dos pacientes na conexão com outras pessoas, afetando também humor e qualidade de vida. A musicoterapia com abordagem em canto coral pode trazer benefícios na reabilitação da linguagem verbal e no convívio social. Método. Foi realizado levantamento de literatura nacional e internacional comparando protocolos de intervenções musicoterapêuticas em canto coral e individual. Resultados. Encontramos nove estudos com abordagens terapêuticas para afasia pós AVC, com intervenções realizadas em grupo de canto coral e individual. Conclusão. Constatou-se a necessidade da realização de mais pesquisas e propostas sobre os benefícios individuais para pacientes com afasia nas intervenções em grupo de canto coral.
\end{abstract}

Unitermos. Afasia de Broca; Afasia Motora; Musicoterapia; Reabilitação do AVC

\begin{abstract}
Introduction. Motor aphasia is one of the recurrent sequelae of cerebrovascular accident impacting patients' verbal communication in connection with other people, also affecting mood and life quality. Music therapy with a choral approach can bring benefits in the rehabilitation of verbal language and social life. Method. A bibliographic survey was carried out in national and international literature comparing protocols for music therapy interventions in choral and individual singing. Results. We found nine studies with therapeutic approaches to aphasia after stroke, with interventions performed in a choir and individual group. Conclusion. There was a need for further research and proposals on individual benefits for patients with aphasia in interventions in a choir group.
\end{abstract}

Keywords. Broca Aphasia; Motor Aphasia; Music Therapy; Stroke Rehabilitation

\section{Resumen}

Introducción. Afasia motora es una de las secuelas recurrentes de un accidente cerebrovascular impactando en la comunicación verbal de los pacientes y en su interacción con otras personas, afectando también el humor y la calidad de vida. La musicoterapia abordada en el canto coral puede traer beneficios en la rehabilitación del lenguaje verbal y en la convivencia social. Método. fue realizado un estudio bibliográfico en literatura nacional e internacional comparando protocolos de intervenciones en musicoterapias en canto coral e individuales. Resultados. encontramos nueve estudios con abordajes terapéuticas para la 
Afasia después del ACV, con intervenciones realizadas en grupo de canto coral e individual. Conclusión. se verifico la necesidad de realizar más investigaciones y propuestas sobre los beneficios individuales para pacientes con Afasia en las intervenciones del canto coral en grupo.

Palabras clave. Afasia de Broca; Afasia Motora; Musicoterapia; Rehabilitación de ACV

Trabalho realizado na Faculdade Santa Marcelina, São Paulo-SP, Brasil.

\section{INTRODUÇÃO}

A alteração na fala, uma das sequelas mais frequentes pós AVC, atinge cerca de $70 \%$ dos pacientes em relação a outras comorbidades, sendo a afasia um dos transtornos de linguagem mais importantes representando 56,1\% dessa população e a afasia motora chega a atingir $31,5 \%{ }^{1-}$ 4. Segundo a classificação da Escola de Afasia de Boston, a afasia motora (Broca) é uma afasia não fluente, assim como a transcortical motora, transcortical mista e a global $^{5}$. Na afasia motora, com compreensão relativamente preservada, ocorrem, em geral, dificuldades de comunicação verbal incluindo restrição de vocabulário, articulação e prosódia e outros comprometimentos que causam grande impacto na expressão do paciente na conexão com outras pessoas ${ }^{1,6}$.

Ante a grande porcentagem de pessoas com sequelas de afasia motora, sendo este o mais presente entre os distúrbios da linguagem, faz-se importante e necessária terapia de reabilitação ${ }^{2-4}$. A musicoterapia (MT) apresenta como recurso terapêutico a prática de canto coral, com efeito benéfico na recuperação da comunicação verbal e com 
evidências na literatura, é uma terapia usada como técnica facilitadora nesse objetivo7,8. A capacidade de cantar é frequentemente preservada em afásicos, o canto, além de ser altamente estimulante, pode ser usado como terapia para expressão das emoções e interação social, combinando processos cerebrais motor-auditivo, auditivos, linguísticos, cognitivos, emocionais e sociais tanto no hemisfério esquerdo (HE) quanto no direito (HD) ${ }^{9}$.

Relacionando a música e a linguagem, Merrett et al. ${ }^{10}$ apresentaram duas teorias como motivos para utilização da música na reabilitação da afasia, a primeira é sobre o processamento compartilhado, que foca nas semelhanças e transferências entre elas e a segunda sobre a especificidade de domínio e dissociações. Sobre a teoria das dissociações, ainda não há explicação como os dois sistemas, que são dissociáveis, poderiam permitir que as redes de música oferecessem suporte à função da linguagem e por outro lado, existem outros estudos que demonstram semelhanças e vínculos entre os componentes da música e da linguagem na comunicação verbal. A musicoterapia neurológica utiliza técnicas padronizadas que promovem efeitos da música na função cerebral e comportamental, uma vez que, os processamentos das duas áreas, música e linguagem verbal, são mediados por circuitos córticos estriatais e envolvem núcleos da base, área motora suplementar, córtex pré-motor e opérculo frontal ${ }^{11}$. O processamento musical promove a integração de áreas corticais do cérebro com estruturas envolvidas na evocação de emoções em regiões cerebrais 
relacionadas ao sistema de recompensa límbico e paralímbico, ativando o hipocampo e o sistema dopaminérgico. Estudos de imagens sugerem que, o processamento musical e o da comunicação verbal na linguagem compartilham os mesmos sistemas neurais, mas que são codificados diferentemente ${ }^{12}$.

O canto coral envolve diferentes áreas cerebrais ativando atenção, memória e emoção, e pode facilitar a comunicação verbal quando são ativados centros de linguagem intactos no HD pela neuroplasticidade ${ }^{7,13}$. O canto coral é bastante empregado para estimular a memória, a expressão, a comunicação, a interação das pessoas no convívio social e melhorar a qualidade de vida, podendo trazer benefícios para pacientes afásicos nas relações sociais, em suas limitações de comunicação verbal, e em atividades de interações e espírito de colaboração entre os participantes $6,7,14$. O objetivo desse estudo foi verificar os benefícios para os pacientes com afasia motora em artigos sobre musicoterapia e canto coral, por meio de revisão de bibliográfica.

\section{MÉTODO}

Para este estudo foi realizada uma revisão bibliográfica com publicações encontradas nas bases de dados Pubmed, Scielo, Researchegate, Lilacs, Bireme, Google, Google Scholar, livros e dissertações. Foram incluídas publicações em língua portuguesa e inglesa com intervenções em 
musicoterapia (MT) com abordagem em canto coral e individual na reabilitação da afasia motora pós AVC e foram excluídas as que não contemplaram essa abordagem. Citações e fontes bibliográficas pesquisadas nos direcionaram à pesquisa de novos materiais de consulta. Os descritores utilizados nas bases de dados foram "Afasia de Broca", "Afasia Motora", "Musicoterapia", "Reabilitação do AVC".

\section{RESULTADOS}

Neste levantamento bibliográfico encontramos nove artigos sobre o canto coral e individual para afásicos ${ }^{8,9,13-19}$. Alguns desses estudos trataram dos benefícios do canto para afasia motora $8,9,13,15,17$, outros incluíram diferentes tipos de $\operatorname{afasia}^{16,18,19}$ e outros não especificaram a afasia ${ }^{13,14}$. O

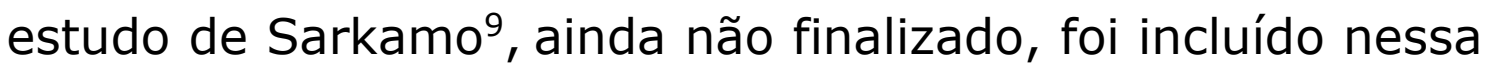
revisão pela relevância do número de participantes, superior aos demais, e pela consistência da abordagem em testar a eficiência do canto coral na reabilitação da comunicação verbal em afásicos, apesar de não apresentar resultados. Os dados descritivos e analíticos dos nove artigos levantados, contendo as informações de autor, objetivo, número de pacientes envolvidos, tipo/gravidade/tempo de afasia, número de sessões realizadas, instrumentos de avaliação, abordagens/intervenções e profissionais envolvidos, são apresentados no Quadro 1 e nos resultados descritos abaixo. 
Quadro 1.

\begin{tabular}{|c|c|c|c|c|c|c|}
\hline autor & Objetivo & $\begin{array}{l}\text { No.Pacientes/ } \\
\text { Tipo/gravidade } \\
\text { /tempo de } \\
\text { afasia }\end{array}$ & $\begin{array}{l}\text { No. } \\
\text { Sessões }\end{array}$ & $\begin{array}{l}\text { Avaliação/ } \\
\text { instrumentos }\end{array}$ & $\begin{array}{l}\text { Abordagem/ } \\
\text { intervenção }\end{array}$ & profissional \\
\hline $\begin{array}{l}\text { Jungblut et } \\
\text { al. }{ }^{16}\end{array}$ & $\begin{array}{l}\text { Investigar os } \\
\text { efeitos do } \\
\text { treinamento } \\
\text { rítmico e } \\
\text { melódico }\end{array}$ & $\begin{array}{l}3 \text { - afasia crônica } \\
\text { grave e apraxia } \\
\text { da fala: } \\
1 \text { motora e } 1 \\
\text { global (AVC) } \\
1 \text { global } \\
\text { (hemorragia } \\
\text { cerebral) } \\
18 \text { meses icto }\end{array}$ & $\begin{array}{l}\text { individual } \\
60 \text { min } \\
2 x \\
\text { semana } \\
6 \text { meses }\end{array}$ & $\begin{array}{l}\text { Tipo e gravidade de } \\
\text { afasia e apraxia da fala } \\
\text { Dados de imagem,a } \\
\text { Aval. Fono: Produção } \\
\text { de ritmo vocal, } \\
\text { Linguagem, } \\
\text { Desempenho motor da } \\
\text { fala. } \\
\text { Análise musical } \\
\text { (realizada por músico } \\
\text { profissional) }\end{array}$ & $\begin{array}{l}\text { SIPARI } \\
\text { (Variação da TEM): } \\
\text { Canto, entonação, } \\
\text { prosódia, } \\
\text { respiração, ritmo e } \\
\text { improvisação. } \\
\text { Treinamento } \\
\text { rítmico e melódico } \\
\text { do canto }\end{array}$ & MT \\
\hline $\begin{array}{l}\text { Akanuma et } \\
\text { al. }{ }^{17}\end{array}$ & $\begin{array}{l}\text { Verificar se o } \\
\text { canto pode } \\
\text { melhorar a } \\
\text { função da } \\
\text { comunicação } \\
\text { verbal pela } \\
\text { análise do } \\
\text { metabolismo } \\
\text { da glicose } \\
\text { nas áreas de } \\
\text { Broca, } \\
\text { Wernicke e } \\
\text { no HD }\end{array}$ & $\begin{array}{l}10 \text { - afasia } \\
\text { motora } \\
\text { Diferentes graus } \\
>3 \text { anos icto }\end{array}$ & $\begin{array}{l}\text { Grupo } \\
30 \text { min } \\
1 x \\
\text { semana } \\
10 \\
\text { semanas }\end{array}$ & $\begin{array}{l}\text { Testes de linguagem } \\
\text { verbal, } \\
\text { PET (em } 6 \\
\text { participantes, devido à } \\
\text { disponibilidade de } \\
\text { horário local) antes e } \\
\text { depois da terapia }\end{array}$ & $\begin{array}{l}\text { Teste de nomeação } \\
\text { e Treinamento de } \\
\text { canto coral: } \\
\text { Melodias } \\
\text { conhecidas com } \\
\text { letras modificadas } \\
\text { usando palavras } \\
\text { que apresentaram } \\
\text { dificuldade de } \\
\text { emissão nos testes }\end{array}$ & MT \\
\hline $\begin{array}{l}\text { Fogg-Rogers } \\
\text { et al. }{ }^{14}\end{array}$ & $\begin{array}{l}\text { Investigar } \\
\text { habilidades } \\
\text { de } \\
\text { linguagem, a } \\
\text { participação } \\
\text { na terapia e } \\
\text { como são as } \\
\text { experiências } \\
\text { dos } \\
\text { participantes } \\
\text { na atividade } \\
\text { conduzida } \\
\text { por um } \\
\text { musicoterap } \\
\text { euta }\end{array}$ & $\begin{array}{l}8 \text { - afasia } \\
\text { gravidade } \\
\text { moderada } \\
3 \text { meses a } 12 \\
\text { anos icto }\end{array}$ & $\begin{array}{l}\text { Grupo } \\
\text { misto }^{\text {b }} \\
6 \text { meses } \\
\text { a } 2 \text { anos }\end{array}$ & $\begin{array}{l}\text { Medidas quantitativas: } \\
\text { afasia, QV, } \\
\text { Participação, } \\
\text { Questionários e } \\
\text { entrevistas } \\
\text { Medida qualitativa: } \\
\text { auto gestão de } \\
\text { condição neurológica, } \\
\text { necessidades, } \\
\text { experiência no coral e } \\
\text { benefícios terapêuticos }\end{array}$ & $\begin{array}{l}\text { Terapia de Canto } \\
\text { coral }\end{array}$ & $\begin{array}{l}\text { MT } \\
\text { Apoio do } \\
\text { organizador } \\
\text { do coral e } \\
\text { fonoaudiolog } \\
\text { ia nas } \\
\text { entrevistas }\end{array}$ \\
\hline $\begin{array}{l}\text { Palazzi et } \\
\text { al. }{ }^{15}\end{array}$ & $\begin{array}{l}\text { Verificar a } \\
\text { efetividade } \\
\text { da } \\
\text { intervenção } \\
\text { MT em } \\
\text { paciente que } \\
\text { havia } \\
\text { participado } \\
\text { de estudo } \\
\text { anteriorment } \\
\text { e. }\end{array}$ & $\begin{array}{l}1 \text { - afasia motora } \\
\text { AVC } \\
7 \text { anos icto }\end{array}$ & $\begin{array}{l}\text { Individua } \\
1 \\
1 \text { hora } \\
2 x \\
\text { semana } \\
3 \text { meses }\end{array}$ & $\begin{array}{l}\text { Diagnóstico de afasia } \\
\text { Avaliações: } \\
\text { Neuropsilin (pré e pós } \\
\text { intervenção, por fono) } \\
\text { Avaliação de discurso } \\
\text { oral (durante } \\
\text { intervenção, por MT) } \\
\text { POMA } \\
\text { Anamnese sonoro } \\
\text { musical }\end{array}$ & $\begin{array}{l}\text { Exercícios de ritmo } \\
\text { e fluência (TEM } \\
\text { adaptada), } \\
\text { composição/recriaç } \\
\text { ão, Improvisação } \\
\text { vocal e } \\
\text { instrumental } \\
\text { Canto e uso de } \\
\text { instrumentos } \\
\text { musicais }\end{array}$ & MT \\
\hline $\begin{array}{l}\text { Hurkmans et } \\
\text { al. }{ }^{18}\end{array}$ & $\begin{array}{l}\text { Aferir a } \\
\text { eficácia da } \\
\text { abordagem } \\
\text { Speech- } \\
\text { Music } \\
\text { Therapy for } \\
\text { Aphasia } \\
\text { (SMTA) na } \\
\text { intervenção } \\
\text { integrada } \\
\text { (fono e MT) }\end{array}$ & $\begin{array}{l}5 \text { - afasia e } \\
\text { apraxia } \\
\text { ( } 3 \text { afasia motora } \\
\text { grau moderado, } \\
1 \text { Wernicke grave } \\
\text { e } \\
1 \text { global grave) } \\
\text { entre } 3 \text { e } 6 \text { meses } \\
\text { icto }\end{array}$ & $\begin{array}{l}\text { Individua } \\
\text { I } \\
30 \text { min } \\
2 x \\
\text { semana } \\
24 \\
\text { sessões: } \\
\text { entre } 12 \\
\text { e } 20 \\
\text { semanas }\end{array}$ & $\begin{array}{l}\text { Precisão, consistência e } \\
\text { fluência da articulação } \\
\text { na comunicação verbal } \\
\text { Testes de controle }\end{array}$ & $\begin{array}{l}\text { SMTA (adaptação } \\
\text { TEM) } \\
\text { Exercícios de fala } \\
\text { Canto (tempo, } \\
\text { métrica, dinâmica, } \\
\text { melodia e ritmo) } \\
\text { Intervenção: } \\
\text { Aquecimento vocal, } \\
\text { Exercícios de fala, } \\
\text { canto rítmico e fala. } \\
\text { Treino em casa } 3 x \\
\text { semana }\end{array}$ & $\begin{array}{l}\text { MT } \\
\text { neurológica } \\
\text { e } \\
\text { fonoaudiolog } \\
\text { ia integradas }\end{array}$ \\
\hline
\end{tabular}


Quadro 1 (cont.).

\begin{tabular}{|c|c|c|c|c|c|c|}
\hline autor & Objetivo & $\begin{array}{l}\text { No.Pacientes/ } \\
\text { Tipo/gravidade } \\
\text { /tempo de } \\
\text { afasia }\end{array}$ & $\begin{array}{l}\text { No. } \\
\text { Sessões }\end{array}$ & $\begin{array}{l}\text { Avaliação/ } \\
\text { instrumentos }\end{array}$ & $\begin{array}{l}\text { Abordagem/ } \\
\text { intervenção }\end{array}$ & profissional \\
\hline $\begin{array}{l}\text { Zumbansen } \\
\text { et al. }{ }^{8}\end{array}$ & $\begin{array}{l}\text { Verificar o } \\
\text { efeito e a } \\
\text { importância } \\
\text { do canto } \\
\text { coral na } \\
\text { reabilitação } \\
\text { da afasia } \\
\text { motora }\end{array}$ & $\begin{array}{l}22 \text { - afasia } \\
\text { motorac } \\
\text { (sendo } 21 \text { AVC) } \\
\text { Diferentes níveis } \\
\text { de gravidade } \\
>1 \text { ano icto }\end{array}$ & $\begin{array}{l}\text { Grupo } \\
2 \mathrm{~h} \\
1 \mathrm{x} \\
\text { semana } \\
26 \\
\text { semanas }\end{array}$ & $\begin{array}{l}\text { Testes de avaliação } \\
\text { fono, Comunicação } \\
\text { funcional, Habilidades } \\
\text { de voz, Linguagem } \\
\text { verbal, Humor e } \\
\text { Qualidade de vida }\end{array}$ & $\begin{array}{l}\text { Aquecimento vocal } \\
\text { Canto coral }\end{array}$ & $\begin{array}{l}\text { Regente } \\
\text { coral }\end{array}$ \\
\hline $\begin{array}{l}\text { Kasdan et } \\
\text { al. }{ }^{19}\end{array}$ & $\begin{array}{l}\text { Determinar } \\
\text { fatores que } \\
\text { podem } \\
\text { influenciar } \\
\text { os recursos } \\
\text { musicais em } \\
\text { afásicos, } \\
\text { isolando a } \\
\text { melodia para } \\
\text { descobrir } \\
\text { seu papel e } \\
\text { eficácia na } \\
\text { terapia. }\end{array}$ & $\begin{array}{l}20 \text { - afasia } \\
\text { (9 motora, } 8 \\
\text { anômica e } 3 \\
\text { Wernicke) } \\
\text { pós AVC }\end{array}$ & $\begin{array}{l}\text { Grupo } \\
(20 \\
\text { afásicos } \\
\text { e } 20 \\
\text { controles } \\
\text { ) Uma } \\
\text { única vez }\end{array}$ & $\begin{array}{l}\text { Testes: tipo e } \\
\text { gravidade de afasia } \\
\text { Questionário: } \\
\text { experiência musical }\end{array}$ & $\begin{array}{l}\text { TEM } \\
\text { Canto: entonação, } \\
\text { prosódia, } \\
\text { respiração, ritmo, } \\
\text { improvisação. } \\
\text { Atuações vocais } \\
\text { (letra cantada, } \\
\text { falada, só melodia) }\end{array}$ & MT e fono \\
\hline $\begin{array}{l}\text { Monroe et } \\
\text { al. }{ }^{13}\end{array}$ & $\begin{array}{l}\text { Examinar se } \\
\text { a } \\
\text { participação } \\
\text { no coral } \\
\text { melhora as } \\
\text { habilidades } \\
\text { de voz, } \\
\text { comunicação } \\
\text { verbal, } \\
\text { funcional, e } \\
\text { participação } \\
\text { social. }\end{array}$ & $\begin{array}{l}\text { Dois estudos } \\
\text { sobre afasiad }{ }^{d} \\
\text { Tamplin et al. }{ }^{20} \text { : } \\
13 \text { - afasia não } \\
\text { especificada; } \\
\text { Zumbansen et } \\
\text { al. }^{8}: \quad 22 \text { - } \\
\text { afasia motora } \\
>1 \text { ano icto }\end{array}$ & $\begin{array}{l}\text { Grupo } \\
2 \mathrm{~h} \\
1 \mathrm{x} \\
\text { semana } \\
20 \\
\text { semanas } \\
26 \\
\text { semanas }\end{array}$ & $\begin{array}{l}\text { Tamplin et al. }{ }^{20} \text { : } \\
\text { Entrevista com } \\
\text { participantes } \\
\text { Ambos os estudos: } \\
\text { Habilidades de voz } \\
\text { Comunicação verbal e } \\
\text { funcional } \\
\text { Participação social }\end{array}$ & $\begin{array}{l}\text { Aquecimento vocal } \\
\text { Canto coral }\end{array}$ & $\begin{array}{l}\text { Tamplin et } \\
\text { al. }{ }^{20}: \mathrm{MT} \\
\text { Zumbansen } \\
\text { et al. }{ }^{8}: \\
\text { Regente } \\
\text { coral }\end{array}$ \\
\hline $\begin{array}{l}\text { Sarkamo } \\
\text { (Não } \\
\text { concluído) }\end{array}$ & $\begin{array}{l}\text { Verificar a } \\
\text { eficácia do } \\
\text { canto coral } \\
\text { nos aspectos } \\
\text { da } \\
\text { linguagem } \\
\text { verbal e nas } \\
\text { questões } \\
\text { cognitivas e } \\
\text { emocionais. }\end{array}$ & $\begin{array}{l}60 \text { - afasia } \\
\text { motora } \\
\text { Pós AVC }\end{array}$ & $\begin{array}{l}\text { Dois } \\
\text { grupos } \\
\text { mistos }^{\mathrm{e}} \\
1,5 \mathrm{~h} \\
1 \mathrm{x} \\
\text { semana } \\
16 \\
\text { semanas } \\
\text { seguidas } \\
\text { por } \\
16 \\
\text { semanas } \\
\text { de } \\
\text { cuidado } \\
\text { padrão }\end{array}$ & $\begin{array}{l}\text { Testes, exames e } \\
\text { questionários: } \\
\text { capacidade de } \\
\text { comunicação, prod. } \\
\text { espont. da fala, } \\
\text { descrição de imagem, } \\
\text { repetição de } \\
\text { palavras/frases, } \\
\text { agilidade verbal, } \\
\text { nomeação/busca de } \\
\text { palavras, compreensão } \\
\text { verbal, habilidade para } \\
\text { cantar e percepção } \\
\text { musical }\end{array}$ & $\begin{array}{l}\text { Canto coral, } \\
\text { Protocolos de fala/ } \\
\text { TEM. } \\
\text { Treino em casa: } 3 x \\
\text { semana/30 minutos }\end{array}$ & MT \\
\hline
\end{tabular}

a. Comparação de dados de imagem com grupo controle (30 saudáveis), antes e depois da intervenção.

b. Coral terapêutico comunitário incluindo diferentes condições neurológicas e voluntários saudáveis.

c. Recrutados de 3 centros de reabilitação, divididos em 3 grupos: coral, grupo controle de teatro e lista de espera.

d. Revisão sistemática com 11 estudos, selecionamos dois que se referem a pacientes afásicos pós AVC.

e. 30 afásicos em cada grupo randomizado. Grupo controle (60 familiares).

No estudo de Jungblut et al. ${ }^{16}$, na comparação pré e pós terapia, os pacientes apresentaram melhoras significativas na gravidade da afasia e apraxia da fala e nas avaliações da 
produção do ritmo vocal, da linguagem e do desempenho motor da fala; os dados de imagem dos pacientes apresentaram importantes ativações peri-lesionais.

Akanuma et al. ${ }^{17}$ avaliaram que, cinco dos dez pacientes, apresentaram melhoras após a intervenção, sendo que três melhoraram após o canto e dois após o canto e o trabalho de nomeação; embora todos apresentassem lesões no núcleo da base no $\mathrm{HE}$, quatro deles, exibiram núcleo da base e lobo temporal esquerdo intactos. Nos exames PET dos cinco pacientes que melhoraram, três apresentaram metabolismo da glicose preservado no lobo temporal direito. Os outros cinco, que participaram do estudo, não tiveram melhoras significativas, sendo que os que apresentavam lesões nos núcleos da base bilaterais ou lesão grave no lobo temporal esquerdo, não demonstraram melhora e até pioraram.

$O$ estudo de Fogg-Rogers et al. ${ }^{14}$ concluiu que os pacientes com gravidade moderada de afasia apresentaram alto grau de dificuldade na comunicação, melhora significativa em todos os domínios em qualidade de vida e, na questão social se mantiveram na média da população estudada. Nas entrevistas, os pacientes descreveram a terapia de canto coral como atividade prazerosa que promove sua inserção social, uma vez que o canto era a única forma fluente de comunicação e a maioria declarou que houve melhora do humor, linguagem verbal, deglutição, respiração e voz e que o fluxo do grupo facilita as habilidades do canto na melodia, palavras e ritmo. 
Palazzi et al. ${ }^{15}$ apontam que a paciente teve pequena melhora em habilidades linguísticas, no índice de fala e na atenção após a intervenção, comparando o início e o final do tratamento. Musicalmente, observou-se melhora na comunicação não verbal e na integração da produção vocal e instrumental.

Hurkmans et al. ${ }^{18}$ verificaram que, após as intervenções SMTA, todos os cinco participantes apresentaram melhora na clareza da comunicação verbal, e a compreensão melhorou em quatro deles. Em três pacientes as habilidades treinadas apresentaram melhora, enquanto outros dois se mantiveram estáveis. Nas medidas de teste de articulação e de repetição, houve melhora significativa em todos os participantes, mas, nem todos obtiveram melhora em articulação dos fonemas e das palavras, medidas de precisão, consistência e fluência. Nenhum paciente apresentou melhora no processamento de linguagem. A gravidade da afasia melhorou em quatro pacientes. Para três dos cinco pacientes nenhuma melhoria foi encontrada nos testes de controle.

Zumbansen et $a{ }^{8}{ }^{8}$ não encontraram benefícios específicos na comunicação funcional, comparado o grupo coral com os outros dois grupos, nas habilidades de fala e linguagem, humor e qualidade de vida. Avaliações individuais indicam mudanças significativas em diferentes participantes, apontando uma correlação significativa entre as melhorias na comunicação funcional e o atendimento a uma variedade de atividades sociais oferecidas pelos centros de reabilitação, dos quais faziam parte. 
Nas atuações vocais avaliadas, Kasdan et al. ${ }^{19}$ verificaram que afásicos e os controles conseguiram acessar melhor a melodia com as letras das músicas na condição cantada do que na melódica ou falada; uma vez que o acesso à melodia é preservado nos afásicos, os resultados sugerem que o canto parece influenciá-los nos distúrbios da linguagem ao tentar acessar a letra das músicas.

Nenhum dos dois estudos da revisão sistemática de Monroe et al. ${ }^{13}$ mediu resultados de comunicação verbal durante situações de conversas. Os resultados foram diferentes e específicos, dependendo do grau de lesão dos participantes. Um dos estudos relatou melhora nas habilidades de comunicação funcional em alguns pacientes, correlacionada à participação em atividades sociais e o outro não relatou mudança significativa nos resultados. Essa revisão aponta uma interação entre os resultados obtidos na comunicação funcional e as melhoras relacionadas ao bem-estar psicológico e psicossocial na participação da terapia em grupo.

No estudo de Sarkamo ${ }^{9}$, os testes, exames e questionários foram realizados com os pacientes antes da intervenção, ainda não finalizado, não traz resultados.

\section{DISCUSSÃO}

Nesta pesquisa bibliográfica foram encontrados múltiplos benefícios da musicoterapia com canto e canto coral no tratamento de pacientes com afasia pós AVC. 
Alguns dos estudos tiveram como público-alvo pacientes que sofreram AVC há mais de um ano8,13-17, a literatura sobre neurorreabilitação sinaliza que a demora para iniciar tratamento multidisciplinar pode comprometer a recuperação do paciente ${ }^{21}$. Estudos apontam que, na fase inicial após o AVC, a reabilitação pode ocorrer em função da restituição das redes neurais lesionadas e, na fase crônica, podem ser recrutadas pelos tecidos neurais intactos, graças à neuroplasticidade ${ }^{7,13,22}$. Sendo assim, quanto mais precoce for o processo de reabilitação, mais significativa pode ser a recuperação de seu comprometimento. O número de participantes de todos os estudos foi bem variado apresentando, no geral, amostras pequenas, comprometendo nos resultados, a eficácia da terapia. Verificou-se heterogeneidade nos tipos de afasia estudados. A maioria dos artigos se remeteu à afasia motora, alguns incluíram outros tipos como receptivas e mistas ${ }^{16,18,19}$, outros estudos não relataram o tipo ${ }^{13,14}$, apenas a gravidade da afasia, não sendo possível, portanto, as comparações nos resultados entre eles.

Nos estudos que trataram sobre o canto coral para afásicos após $A V C^{8,9,13,14,17,19}$, foram encontrados diferentes objetivos, não havendo parâmetro de comparação entre eles, o que traz dificuldade para se chegar a um consenso em relação aos benefícios apresentados. Artigos que examinaram os efeitos do canto coral na comunicação verbal $^{8,13,14,17}$ apresentaram resultados diferentes devido às escolhas dos instrumentos de avaliação e apenas um estudo ${ }^{9}$ 
utilizou testes, exames e questionários como instrumentos para avaliar comunicação verbal na afasia motora antes da intervenção coral, porém ainda não foi concluído e não apresenta resultado. O estudo de Akanuma et al. ${ }^{17}$ aponta melhora na comunicação verbal apenas em pacientes com afasia motora que apresentaram estruturas cerebrais preservadas comprovada pela recuperação de palavras após a intervenção das músicas cantadas no coral, e o estudo de Fogg-Rogers et al. ${ }^{14}$ aponta que os pacientes com gravidade moderada de afasia apresentaram alto grau de dificuldade na comunicação. No estudo de Zumbansen et al. ${ }^{8}$, que faz parte também da revisão sistemática de Monroe et al. ${ }^{13}$, não foram encontrados benefícios específicos nas habilidades de fala e linguagem, porém as avaliações individuais indicaram mudanças em alguns participantes sendo provável que regiões específicas, volume de lesão e, consequentemente, graus de afasia apresentem necessidades específicas muitas vezes não abordadas em terapias de grupo. O outro estudo da revisão sistemática ${ }^{13}$ relatou que os instrumentos de avaliação não foram suficientes para detectar mudanças significativas nos resultados para comunicação verbal. Os dois estudos ${ }^{8,13}$ avaliaram comunicação funcional, mas não foram encontrados benefícios específicos para essa medida, porém relataram melhora para alguns pacientes correlacionada à participação em atividades sociais. O estudo de Kasdan et al. ${ }^{19}$ foi o único entre todos a avaliar fatores que podem influenciar os recursos musicais em afásicos nas condições de canto, fala e melodia; nos resultados, o acesso 
à melodia pareceu facilitar a busca das letras das músicas, dado pelo processamento musical no hemisfério direito preservado na afasia, apontando melhoras na condição cantada, isto é, letra e melodia juntas. Não encontramos parâmetros similares em outros estudos com avaliação semelhante a essa para comparação dos achados.

Foram incluídos nesta revisão artigos com intervenções individuais ${ }^{15,16,18}$ para se obter mais dados sobre os efeitos do canto para afasia motora e encontramos resultados similares referentes à precisão, consistência e fluência da articulação na comunicação verbal. Todos fizeram uso de protocolos com variações da Terapia de Entonação Melódica (TEM). Jungblut et al. ${ }^{16}$ realizaram abordagens pelo método SIPARI fazendo uso de canto, entonação, prosódia, respiração, ritmo e improvisação baseada no treinamento rítmico-melódico; nesse estudo além da afasia, os pacientes apresentavam apraxia da fala, na qual é recomendado o treino rítmico pelo nível de exigência à capacidade motora e cognitiva podendo ser um suporte no acesso à fala. O estudo de Palazzi et al. ${ }^{15}$ apresentou intervenções da musicoterapia baseadas em canto, utilizando recursos de canções familiares, improviso e criação, e o de Hurkmans et al. ${ }^{18}$ integrou fonoaudiologia e musicoterapia neurológica no protocolo de intervenção SMTA, com base nas semelhanças entre linguagem e música. Nas avaliações, em dois destes $\operatorname{artigos}^{16,18}$, os pacientes apresentaram melhora significativa na comunicação verbal, provavelmente pela utilização de recursos rítmicos, uma vez que estudos encontrados na 
literatura confirmam déficits em relação à estruturação temporal da fala em pacientes com afasia motora apresentando problemas com o ritmo e a percepção do tempo. Porém, no outro artigo com intervenção individual ${ }^{15}$, com propostas musicais mais melódicas, os resultados indicaram pouca diferença antes e após a terapia, provavelmente devido à paciente demonstrar incômodo e dificuldade com improviso e criação, salientando que a paciente já havia atingido boa melhora em tratamento realizado anteriormente.

As abordagens de canto e de canto coral foram realizadas por musicoterapeutas, sendo que algumas delas, em parceria com profissional de fonoaudiologia para avaliar aspectos da $\operatorname{voz}^{14,16,18,19}$, com exceção de uma que foi conduzida por regente $\mathrm{coral}^{8}$. Embora a fonoaudiologia seja a terapia mais usada para recuperação vocal, a musicoterapia tem apresentado benefícios na reabilitação da comunicação verbal, com o uso de canções por meio da prosódia e articulação, também presentes na linguagem verbal, podendo reorganizar as estruturas que foram lesionadas ${ }^{7,17}$. Todas as intervenções em grupo utilizaram protocolos de canto coral, e dois deles incluíram a TEM ${ }^{9,21}$, bem como os estudos com atendimentos individuais ${ }^{15,16,18}$, com adaptações e variações dessa terapia. A TEM é uma técnica realizada pela fonoaudiologia, em geral como intervenção individual, propondo variações melódicas limitadas com pequenos intervalos para se aproximar da entonação da fala pela prosódia; junto à melodia, bate-se a 
pulsação com a mão esquerda acompanhando as sílabas entoadas para ativar a fluência verbal por meio do ritmo ${ }^{15}$. A TEM sempre foi a técnica mais utilizada para afasia motora até se iniciarem pesquisas constatando que a reabilitação feita pela fonoaudiologia traz alguns progressos para a linguagem mas, que a musicoterapia poderia acessar e ativar áreas cerebrais complementares em que se dá a comunicação verbal permitindo a recuperação de palavras pelo treinamento do canto por intermédio da melodia e do ritmo ${ }^{17}$. Nas intervenções constatamos a importância da presença do musicoterapeuta com a utilização de suas múltiplas abordagens musicais no canto, seja individual ou coral, trazendo estímulo aos pacientes na recuperação de suas habilidades, como apontado na literatura?.

Finalmente, salientamos os benefícios sociais relatados pelos autores, uma vez que as intervenções musicais realizadas pelo musicoterapeuta promovem o estimulo das áreas cerebrais envolvidas com a emoção e controle motor ${ }^{12}$, contribuindo para a melhora do paciente no seu humor e fatores emocionais, com a promoção da interação social ${ }^{7}$. Estudos avaliaram e relataram os benefícios sociais e recuperação de habilidades de linguagem de afásicos que fazem parte de coral comunitário nos quais, os pacientes descreveram melhorias no campo emocional e social que facilitaram as habilidades funcionais e a indicação da redução de isolamento social e melhora do bem-estar, promovidas pelas intervenções em grupo, correlacionando essa interação 
com os resultados funcionais, promovidos pelo canto coral $^{8,13,14}$.

\section{CONCLUSÃO}

Encontramos na pesquisa a indicação que o canto, individual ou em grupo coral, é uma terapia estimulante e agradável para a interação social de pacientes com afasia motora e pode trazer benefícios na comunicação verbal e funcional, mesmo que não tenham sido encontrados estudos conclusivos de sua eficácia. Faz-se necessário estudos com melhor desenho metodológico, que determinem grupo controle, tipos de afasia e avaliações específicas para que as indicações terapêuticas sejam mais direcionadas e protocolos bem definidos, assim como o envolvimento da musicoterapia no tratamento de forma precoce. Verificamos resultados positivos nos aspectos sociais obtidos na inclusão de participantes saudáveis no canto coral. Como os estudos são limitados, faz-se necessária mais investigações sobre os benefícios do canto coral na comunicação verbal de afásicos.

\section{REFERÊNCIAS}

1.Scherer LC, Gabriel R. Processamento da linguagem: contribuições da neurolinguística. Signo 2007;32:66-81.

https://www.researchgate.net/publication/277155897 PROCESSAME NTO DA LINGUAGEM CONTRIBUICOES DA NEUROLINGUISTICA

2.Talarico TR, Venegas MJ, Ortiz KZ. Perfil populacional de pacientes com distúrbios da comunicação humana decorrentes de lesão cerebral, assistidos em hospital terciário. Revista CEFAC 2011;13:330-9.

https://doi.org/10.1590/S1516-18462010005000097 
3. Lima CMG, Silva HPW, Silva de Souza PA, Amaral TLM, Prado PR. Características epidemiológicas e clínicas dos pacientes acometidos por acidente vascular cerebral. J Health Sci Inst 2015;33:45-9.

https://www.unip.br/presencial/comunicacao/publicacoes/ics/edicoes /2015/01_jan-mar/V33 n1 2015_p45a49.pdf

4. Oliveira JG, Damasceno KG, Souza LP, Lima MG. Perfil clínico epidemiológico e os principais rótulos diagnósticos de enfermagem aos pacientes internados com acidente vascular cerebral em um hospital de grande porte na região sul da Amazônia legal. Amaz Sci Health 2016;4:3-11.

http://repositorio.facimed.edu.br/xmlui/bitstream/handle/123456789 188/1106-4930-1-PB.pdf?sequence =1\&isAllowed =y

5.Beber BC. Proposta de apresentação da classificação dos transtornos de linguagem oral no adulto e no idoso. Distúrb Comun 2019;31:1609. http://dx.doi.org/10.23925/2176-2724.2019v31i1p160-169

6. Penteado RZ, Barbosa Penteado LAP. Percepção da voz e saúde vocal em idosos coralistas. Rev CEFAC 2010;12:1-11.

http://dx.doi.org/10.1590/S1516-18462009005000053

7.Drake J. Music Therapy and Communication Disabilities: Singing, Speech, and the Brain (Thesis). Bridgewater: Bridgewater State University, 2014,74p. http://vc.bridgew.edu/honors proj/74

8.Zumbansen A, Peretz I, Anglade C, Bilodeau J, Généreux S, Hubert $M$, et al. Effect of choir activity in the rehabilitation of aphasia: a blind, randomised, controlled pilot study. Aphasiology 2017;31:800-900.

http://dx.doi.org/10.1080/02687038.2016.1227424

9.Sarkamo T. Choir Singing in Aphasia Rehabilitation. Finlândia: University of Helsinki. Clinical trials 2018.

https://clinicaltrials.gov/ct2/show/NCT03501797

10.Merrett DL, Zumbansen A, Peretz I. A theoretical and clinical account of music and aphasia. Aphasiology 2019;33:379-81.

https://doi.org/10.1080/02687038.2018.1546468

11.Lee YS, Thaut C, Santoni C. Neurologic Music Therapy for Speech and Language Rehabilitation. The Oxford Handbook of Music and Brain. Oxford University Press. 2018.

https://doi.org/10.1093/oxfordhb/9780198804123.013.28

12.Rocha VC, Boggio OS. A música por uma ótica neurocientífica. Belo Horizonte: Per Musi 2013;27:132-40.

http://dx.doi.org/10.1590/S1517-75992013000100012

13. Monroe $\mathrm{P}$, Halaki M, Kumfor F, Ballard KJ. The effects of choral singing on communication impairments in acquired brain injury: $A$ systematic review. Int J Lang Commun Disord 2020;55:303-19.

https://doi.org/10.1111/1460-6984.12527

14.Fogg-Rogers L, Buetow S, Talmage A, McCann CM, Leão SHS, Tippett $L$, et al. Choral singing therapy following stroke or Parkinson's disease: an exploration of participants' experiences. Disabil Rehabil 2015;38:952-62.

https://doi.org/10.3109/09638288.2015.1068875

15.Palazzi A, Fontoura D. Musicoterapia na afasia de expressão: um estudo de caso. Rev Bras Musicoter 2016;20:50-70. 
http://www.revistademusicoterapia.mus.br/wp-

content/uploads/2016/10/3-Musicoterapia-na-afasia-deexpress\%C3\%A3o-um-estudo-de-caso.pdf

16.Jungblut $M$, Huber $W$, Mais $C$, Schnitker R. Paving the Way for Speech: Voice-Training-Induced Plasticity in Chronic Aphasia and Apraxia of Speech-Three Single Cases. Neural Plasticity 2014: ID841982. http://dx.doi.org/10.1155/2014/841982

17.Akanuma K, Meguro K, Satoh M, Tashiro M, Itoh M. Singing can improve speech function in aphasics associated with intact right basal ganglia and preserved right temporal glucose metabolism: Implications for singing therapy indication. Inter J Neurosci 2016;126:39-45.

https://dx.doi.org/10.3109/00207454.2014.992068

18. Hurkmans J, Jonkers R, Bruijn M, Boonstr AM, Hartman PP, Arendzen $H$, Reinders-Messelink HA. The effectiveness of Speech-Music Therapy for Aphasia (SMTA) in five speakers with Apraxia of Speech and aphasia. Aphasiology 2015;29:939-64.

http://dx.doi.org/10.1080/02687038.2015.1006565

19.Kasdan A, Kiran S. Please, don't stop the music song completion in patients with aphasia. J Comm Dis 2018;75:72-86.

https://dx.doi.org/10.1016/j.jcomdis.2018.06.005

20.Tamplin J, Baker F, Jones B, Way A, Lee S. 'Stroke a chord': The effect of singing in a community choir on mood and social engagement for people living with aphasia following a stroke. NeuroRehabilitation 2013;32:929-41. https://doi.org/10.3233/NRE-130916

21.Anaya MA, Branscheidt M. Neurorehabilitation after stroke. Stroke 2019;50:e180-1.

https://dx.doi.org/10.1161/STROKEAHA.118.023878

22. Meulen I, Sandt-Koenderman ME, Ribbers GM. Melodic intonation therapy: Present controversies and future opportunities. Arc Phys Med Rehab 2012;93:46-52. https://doi.org/10.1016/j.apmr.2011.05.029 